\title{
Development of a participation style scale for online instructional discussions
}

\author{
Ferhat Kadir Pala ${ }^{1}$ (D) Mukaddes Erdem ${ }^{2}$ \\ Published online: 12 August 2020 \\ (c) Association for Educational Communications and Technology 2020
}

\begin{abstract}
The purpose of this study is to develop a standardized measurement tool that can be used to determine the participation styles of individuals participating in online instructional discussions. The scale consists of two dimensions called 'Why' and 'How.' The Why dimension comprises the main motivators of the participants' participation in online instructional environments, whereas the How dimension comprises items expressing participation behaviors or forms. Two separate datasets were used for exploratory factor analysis (450 participants) and confirmatory factor analysis (693 participants), and the scale was applied to both undergraduate and graduate students. The scale consisted of eight factors, with four in the Why dimension and four in the How dimension. The results of confirmatory factor analysis showed that the scale was able to identify four different patterns of participation. Expressed as participation styles, these patterns are To Socialize/Connective, To Get Information/Analytical, To Discuss/Innovative, and To Fulfill Requirements/Practical. According to these results, the Participation Style Scale for Online Instructional Discussions was assumed to be a valid and a reliable measurement tool for determining the participation styles of participants of online instructional discussions. These four styles are thought to contribute to the instructors, the researchers, and the learners who want to benefit from effective learning in online environments. Instructors and researchers can determine learners' participation styles before organizing discussion environments, and learners who think and gain awareness about their own participation styles can manage their discussion and learning processes more effectively.
\end{abstract}

Keywords Online discussion · Online instructional discussion · Participation style · Participation style scale $\cdot$ Scale development

Electronic supplementary material The online version of this article (https://doi.org/10.1007/s1142 3-020-09817-x) contains supplementary material, which is available to authorized users.

Ferhat Kadir Pala

fkpala@gmail.com

1 Faculty of Education, Computer Education and Instructional Technology Department, Aksaray University, B Blok, Room B113, 68100 Aksaray, Turkey

2 Computer Education and Instructional Technology Department, Hacettepe University, Ankara, Turkey 


\section{Introduction}

The global education system has evolved into distance education. As of July 23, 2020, UNESCO (2020) reported that there have been 1,066,817,855 learners affected by the COVID-19 pandemic, or $60.9 \%$ of the world's total enrolled learners. Individuals began to worry about COVID-19 as it has an extremely high infection rate and relatively high mortality rate. Thus, many institutions have opted to cancel all face-to-face classes and have mandated that faculty move their courses online to help prevent the spread of the virus that causes COVID-19 (Hodges et al. 2020). Educational institutions accordingly need to strengthen the practices in their curricula and make them more sensitive to the distance learning needs of students (Toquero 2020). Students benefit from both asynchronous learning (Daniel 2020) and synchronous learning (Huang et al. 2020) via remote learning support, equity and access, assessments, and attention to a range of student needs and special populations (Reich et al. 2020). One of the user-managed environments that developed with Web 2.0 technology is online discussion forums. Online discussion environments that have transcended the question-and-answer process and have undertaken the function of creating common information can meet these needs by increasing interaction. Garrison, Anderson, and Archer (1999) described this situation with the concept of 'teaching presence' in their study. The scale developed in this study aims to determine the style of participation in instructional discussion environments in such a context. Thus, this study may provide an opportunity to design better online discussion environments and increase online participation for more effective and productive learning.

Due to the fact that online discussion forums are participant-led and enable detailed discussions on a particular topic, their possibilities and ways of use for instructional purposes are emphasized, and their effectiveness is being tested. Defined by Valiathan as a technology-based technique facilitating the transfer of implicit knowledge through interactions between learners and teachers (cited in Mason 2011), online discussion environments encourage even the most reticent students to participate (Citera 1998), positively affect learning, increase satisfaction and retention (Alavi and Dufner 2005), and support studentcentered learning (Davies and Graff 2005). However, it is necessary to consider various factors such as social relations in discussion environments, whether the discussion topic is related or not related to the content of the course, motivation of students, ability to use language, communication skills within the group, and gender differences (Lin et al. 2019; Rosé and Ferschke 2016; Ruthotto et al. 2020; Wise and Cui 2018).

Although online discussion environments have educational benefits such as structuring information, developing different perspectives, developing critical and reflective thinking, and facilitating peer-to-peer interaction and knowledge transfer (Butcher et al. 2020), the most important problem for more effective learning in these environments is participation and interaction (Cheong and Cheung 2008; Ho 2002). Hence, a discussion environment should be designed primarily to motivate participation. As revealed by Pala and Erdem (2015a) as a result of focus group discussions with students, participation forms require a thorough examination of many themes such as hierarchical structures, feedback systems, discussion topics, follow-up to comments, expression of instant reactions, and visual design. Based on Wenger's definition of participation as participating in an activity, sharing, or being part of a process in an activity with others, Hrastinski (2009) refers to participation as a complex process that involves making, speaking, thinking, feeling, and belonging. In other words, learner participation is a learning process defined by taking part in the environment and maintaining relationships with others (Hrastinski 2006, 2008a). After 
the precondition of participation, individual characteristics such as participation behaviors, goals, expectations, interests, attitudes, and interaction styles will also affect the learning in this complex process taking place in online discussion environments. This study discusses this second dimension and the reasons for participation and how it is realized.

\section{Literature review}

As Pala and Erdem (2015b) point out, the studies examining this process have generally undertaken a classification or relationship search process based on the participation performances of learners in online discussions. Bento, Brownstein, Kemery, and Zacur (2005) mention two different types of interactions. The first of these is called learner-content interaction (Moore 1989) or content interaction (Berge 1995), which refers to the learner creating and reflecting his or her own thoughts by reading the course materials and messages sent. The second is called learner-learner interaction or learner-instructor interaction (Moore 1989) or interpersonal interaction (Berge 1995). This latter type entails the interactions between learners themselves or between the learners and the instructor. Accordingly, Bento and Schuster (2003) and Bento et al. (2005) divided participation types into four, with reluctant, implicit, social, and active participants.

Zuckerman et al. (2009), who examined online participation in terms of need, divided the types of participants into two groups: project producers and social participants. Ruthotto et al. (2020) examined participation regarding the demographic characteristics of participants and they distinguished between active (contributions) and passive (viewership) participation and lurking behavior. Rafaeli and Ariel (2008) examined the contributions made in Wiki environments and classified the participants into three groups as those contributing content, those involved in the community, and lurkers. In their study, Yang and Richardson (2008) gave students mandatory tasks online and classified online participants according to three different styles based on their interactions in the environment. These were active interaction, vicarious interaction, and mixed-balanced interaction styles. In his study examining the participation patterns in online discussion environments, Taylor (2002) identified participants as workers, lurkers, and shirkers.

Gerbic (2006) mentions three types of participation in the literature. The first is called lurking. This categorization is used for those who only follow messages without contributing to the environment. The second refers to participants reading messages, reflecting on them, and then conveying their own views to the environment. This is called reflective monologue. The third involves engaging in an interactive and constructive way, which is called multi-vocal participation. In recent studies on participation patterns in online discussions, some researchers examined participation patterns in terms of language use (Epp et al. 2017; Dowell et al. 2015; Joksimović et al. 2015; Lin et al. 2019; Wise and Cui 2018). For example, Wise et al. (2014) defined online participation as listening and speaking in their work. 'Disregardful,' 'Coverage,' 'Focused,' and 'Thorough' were specified as listening patterns.

Conducting a meta-analysis on learner participation, Hrastinski (2008b) determined that learner participation is discussed within six categories: accessing the environment, writing a message, writing a qualified message, writing and reading a message, writing a message according to the current importance of the subject, and participating in the dialogues felt to be beneficial. Similarly, Pala and Erdem (2015b) discussed the number of messages sent by learners, the number of times accessing the learning environment, the number of 
qualified messages, the number of written and read messages, the number of messages written according to the perceived importance of the subject at the moment, the length of time spent in the environment, the length of the discussion, learner perceptions, and the number of dialogues entered as interaction-based indicators in the determination of online participation.

As can be seen, there are many studies in the literature about participation forms in online discussion environments and categorizations of participants according to certain characteristics. However, log analysis of learning environments comes to the forefront in many of these studies. Therefore, definitions were made by log records of the behaviors of individuals in the environment (Song et al. 2019). The present study was carried out with the idea that studies based on log analysis should be supported by scales based on selfdefinition to be administered to the participants. Hew and Cheung (2012) did state that a rubric can be used in online discussions to reveal the participation of learners in different categories. However, they suggested that this rubric should contain qualitative definitions instead of quantitative criteria and emphasized that it should be valid and reliable. Within the scope of the present study, a scale of participation styles that will be used to determine the types of participants based on user expressions was developed. Style studies aim to at least identify learners in terms of certain characteristics and develop appropriate strategies for them. Learning styles are among them, and individuals with different learning styles are expected to exhibit different behavioral patterns in learning environments. However, learning styles are not sufficient to explain participation in online processes (Pala and Erdem 2011). Participation behaviors are considered to be re-studied within their own structures, and this study is directed towards this purpose. It is thought that participation styles, as the sum of individualistic characteristics such as individuals' needs, expectations, preferences, tendencies, and behaviors, can explain participation processes and performances in online discussion environments and guide those who want to benefit from these environments to support their learning processes.

Participation is a form of action, and like all actions, the subject is influenced by the meaning, expectation, and relationships it establishes with its object. Individuals can evaluate online instructional environments as a means of self-expression and social communication. They can discuss a topic from different perspectives and see it as an environment that provides the opportunity to gain breadth of view and learn more effectively. They can perceive them as flexible environments in which they can freely discuss their new and authentic ideas and in which they can influence others. However, they can also consider them as dysfunctional environments that they have to participate in, which will contribute nothing to them. An individual with the first of these four perceptions is expected to be more interested in the content of the comments of others. The second is expected to focus on formal discussion and perhaps to conduct additional research. The third is expected to add his or her subjective perception and experiences to comments, and the fourth is expected to remain as short a time as possible to fulfill his or her requirements. The scale and its development process, developed with such an intellectual infrastructure, are explained below.

\section{Methodology}

The participation style scale for online instructional discussions consists of two dimensions, called 'Why' and 'How,' and a total of eight factors. The Why dimension includes 14 items about why individuals participate in online instructional discussion environments 
and what their primary aims and expectations are. The How dimension includes 18 items about individuals' participation behaviors in online environments, or, in other words, how they participate in these environments.

\section{Development of the scale}

When creating the scale, first the item pool was created and then expert opinion was taken regarding the items selected from the item pool. As a basis for the formation of scale items, students studying in the Computer Education and Instructional Technology Department were asked to write down their "Thoughts and expectations about participation in online learning environments" since they actually had experience in instructional online discussion environments. In the same department, the notes from an online discussion were examined. In addition, focus group interviews were conducted with the students. Thirdyear students were having online discussions every week for the Special Instructional Methods-II course. First 17 students from this course and then 15 students were interviewed on a volunteer basis. Then, according to the number of comments they sent to the discussions, the 12 students who participated the most in the discussions were interviewed. In order to get the views of the lurkers, nine students who did not send any messages to the environment were also interviewed. Therefore, a total of four focus group interviews were conducted with semi-structured questions. The comments made during the focus group interviews, and especially those of the nine students who participated implicitly, suggested that the 'why' factor may be determinant in participating in online forums. Although log records provide data on the types of participation as mentioned above, they do not contain information on the reasons for this, which is insufficient for guiding the design processes. In this study, although online participation was mandatory for students who participated in the focus group interviews, students who do not participate are thought to have strong reasons, and students were asked about this in focus group interviews. The answers, such as those for item 2, item 12, item 19, item 28, etc., were found to constitute one of the basic dimensions of the scale, 'Why.' On the other hand, the students participating in the focus group interviews were also asked how they participated. Opinions of all students who participated or did not participate in the discussions were gathered and some items, such as item 7 , item 8 , item 14 , item 16 , item 22 , item 30 , item 32 , etc., were obtained that showed 'How' they participated.

Based on the experiences, thoughts, and expectations determined by the focus group interviews, the review of discussion notes, and a detailed literature review, items were created to express the reasons for participation and the forms of participation.

The items were presented to eight academicians working on or teaching in online environments so that they could review the items in terms of whether or not they are understandable and measure what they are supposed to measure. In addition, for understandability and face validity with member checking, the scale was pre-administered to two graduate ( 1 male, 1 female) and seven undergraduate ( 5 males, 2 females) students since the scale would be applied to undergraduate and graduate students. According to those views, a scale of 52 items was obtained as a result of correcting or removing items that were not understood and those that overlapped (additional data are given in Online Resource 1).

After the pilot application (first study group), items that loaded more than one factor in both dimensions and those that loaded less than 0.40 were removed from the scale (Çokluk et al. 2010) (additional data are given in Online Resource 2). The procedure was repeated 
and a 32-item scale was obtained with 14 items in the 'Why' dimension and 18 items in the 'How' dimension. That scale was then applied to the second study group.

The scale consists of two parts: demographic information and scale items. Scale items were prepared in 5-point Likert type. The options are 'not suitable for me at all,' 'not suitable for me,' 'undecided,' 'suitable for me,' and 'very suitable for me.' The scale was applied in Turkish (additional data are given in Online Resource 3).

\section{Study groups}

Two separate datasets were used for exploratory factor analysis (EFA) and confirmatory factor analysis (CFA). Participants of the first study group were students who were continuing their education at undergraduate and graduate levels at 15 different universities in Turkey. At the end of the administration of the scale, 462 participants' data were collected. The scale was completed in printed form by 184 participants, whereas the others completed it online. Some of the participants who explained that they had never participated in online instructional discussions and outliers' answers (incomplete forms in the dataset and observations with a $\mathrm{z}$ score of \pm 4.0 or more) were removed from the data. The EFA was applied to 450 participants' data.

The second study group consisted of undergraduate and graduate students who were studying at 24 different Turkish universities during the 2018-2019 academic year. During the implementation process, data from 703 participants were obtained. The scale was completed in printed form by 148 participants, while 555 participants completed it online. Participants who completed the scale but stated that they had not participated in online instructional discussions before and those whose data were calculated as outliers were excluded from the study. Therefore, the CFA continued with the data from 693 participants.

\section{Data analysis}

In the first phase, it was examined whether the data obtained by administering the scale met the normality assumptions. For this reason, first the Kolmogorov-Smirnov normality test was examined. The Kolmogorov-Smirnov test showed that the datasets were not normally distributed. Huck (2012, p. 27) states that the skewness and kurtosis values of data should be within -1.0 and +1.0 to show normal distribution. Therefore, skewness and kurtosis values were also examined. According to Huck (2012) and Tabachnick and Fidell (2012, p. 87), since these values were within -1.0 and +1.0 , it was concluded that normal distribution could be assumed.

In the next phase, EFA and CFA were performed. Both factor analysis processes are explained in the Results section.

\section{Results}

\section{Exploratory factor analysis}

The EFA was conducted separately for the 'Why' and 'How' dimensions of the scale. First of all, the Kaiser-Meyer-Olkin (KMO) measure of sampling adequacy test and the Bartlett sphericity test were conducted for the 14 items forming the Why dimension and 18 items 
forming the How dimension. These values were $\mathrm{KMO}=0.80, \chi^{2}=1386.91, \mathrm{p}=0.00$ for the Why dimension and $\mathrm{KMO}=0.81, \chi^{2}=1513.24, \mathrm{p}=0.00$ for the How dimension. The results showed that the dataset was suitable for factor analysis (Çokluk et al. 2010).

In the EFA, principal component analysis was applied with the varimax rotation method (Osborne 2015) with the eigenvalue of the items over 1. Four-factor structures were formed in both dimensions. According to the findings of the EFA, the Why dimension explained $53.58 \%$ of the total variance, whereas the How dimension explained $54.31 \%$ of the total variance.

Factors related to the Why dimension of the Participation Style Scale for Online Instructional Discussions and factor loading values obtained by the varimax vertical rotation method regarding the items are presented in Table 1 . The items of the factors forming the Why dimension are presented in Table 2.

According to Table 2, the first 'Why' factor consists of items related to participating to get attention, to see the responses to one's comments, and to confirm one's thoughts. From this point of view, it was concluded that the other people in the environment and the social interaction in the environment were important for these participants, and the factor was therefore named 'To Socialize.'

The items loaded on the second 'Why' factor related to believing that effective learning takes place through discussions, better understanding the subject of the thread, and participating more when the instructor is online. From this point of view, it can be said that the participants directed towards these items interact with the content and the instructor rather than the other people and use the environment for learning purposes. For this reason, this factor is called 'To Get Information.'

The third factor consisted of items such as commenting when necessary to clarify something, having a different point of view, thinking that the subject of the thread will be beneficial, and encountering controversial discussion questions. It is thought that

Table 1 EFA results of the Scale's Why dimension

\begin{tabular}{|c|c|c|c|c|}
\hline \multirow[t]{2}{*}{ Items } & \multicolumn{4}{|c|}{ Factors } \\
\hline & 1 & 2 & 3 & 4 \\
\hline \multicolumn{5}{|c|}{ Rotated data matrix of the Why dimension } \\
\hline i1 & 0.80 & & & \\
\hline i2 & 0.73 & & & \\
\hline i3 & 0.66 & & & \\
\hline i4 & 0.56 & & & \\
\hline i10 & & 0.72 & & \\
\hline i11 & & 0.69 & & \\
\hline i12 & & 0.57 & & \\
\hline i17 & & & 0.76 & \\
\hline i18 & & & 0.64 & \\
\hline i19 & & & 0.58 & \\
\hline i20 & & & 0.48 & \\
\hline i26 & & & & 0.77 \\
\hline i27 & & & & 0.49 \\
\hline i28 & & & & 0.70 \\
\hline
\end{tabular}


Table 2 Why dimension items

\begin{tabular}{lll}
\hline No. & Item & Factor \\
\hline Why dimension & & \\
i1 & I make a comment because I like to get attention & To socialize \\
i2 & I participate because I wonder how my comments will affect & \\
the discussion & \\
i3 & I make a comment to confirm my thoughts & \\
i4 & I participate because I wonder the responses to my comments & \\
i10 & I participate because I believe effective learning takes place & To get information \\
i11 & through discussion & \\
i12 & I participate to better understand the subject of thread & \\
i17 & My participation rate increases when the instructor is online & \\
i18 & I make a comment when I need to clarify & To discuss \\
i19 & I make a comment if my view is different from other's views & \\
i20 & I participate if I think the subject of thread is beneficial for & \\
i26 & me & \\
i27 & I participate when the discussion questions are controversial & \\
i28 & I participate because I feel responsible for the course & To fulfill requirements \\
\hline & I participate because I feel responsible for the other people & \\
who participates the environment & \\
\hline
\end{tabular}

individuals with this style view or want to view online environments as environments that are different and authentic. This factor is named 'To Discuss' since individuals with this style participate when they think they can contribute to the discussions under these conditions.

The fourth 'Why' factor includes items expressing an individuals' tendencies to feel responsible towards the course or others and to participate in the environment in order to show that they are following the course. It can be said that the participants who are directed towards these items have external reasons rather than their own determined goals or participating willingly. Participation is a task for them. The factor was named 'To Fulfill Requirements.'

The results of the EFA related to the How dimension of the scale, which was created to determine participation form as the other component of online participation style, are presented in Tables 3 and 4.

As can be seen from Table 4, the How dimension of the Participation Style Scale for Online Instructional Discussions consists of four factors. The first 'How' factor consists of participatory items about summing up other comments, using others' previous comments to write new comments, being the first commentator so as not to repeat others' comments, and sending motivating messages to others. It can be said that individuals who exhibit these participation behaviors have continuous inspiring and motivating interactions with other participants. From this point of view, individuals who exhibit these behaviors and this factor are called 'Connective.'

The second 'How' factor includes items about making a comment after understanding everything about the subject, going through an intensive thinking process, and paying attention to being understood. It can be said that the interaction of individuals with these 
Table 3 EFA analysis results of the Scale's How dimension

\begin{tabular}{|c|c|c|c|c|}
\hline \multirow[t]{2}{*}{ Items } & \multicolumn{4}{|c|}{ Factors } \\
\hline & 1 & 2 & 3 & 4 \\
\hline \multicolumn{5}{|c|}{ Rotated data matrix of the How dimension } \\
\hline i5 & 0.79 & & & \\
\hline i6 & 0.52 & & & \\
\hline i7 & 0.64 & & & \\
\hline i8 & 0.65 & & & \\
\hline i9 & 0.72 & & & \\
\hline i13 & & 0.63 & & \\
\hline i14 & & 0.57 & & \\
\hline i15 & & 0.76 & & \\
\hline i16 & & 0.71 & & \\
\hline $\mathrm{i} 21$ & & & 0.55 & \\
\hline i22 & & & 0.67 & \\
\hline i23 & & & 0.59 & \\
\hline i24 & & & 0.68 & \\
\hline i25 & & & 0.69 & \\
\hline i29 & & & & 0.62 \\
\hline $\mathrm{i} 30$ & & & & 0.66 \\
\hline $\mathrm{i} 31$ & & & & 0.79 \\
\hline $\mathrm{i} 32$ & & & & 0.65 \\
\hline
\end{tabular}

participation behaviors is more intense, and they care about details. This group, which goes through a more analytical thinking process than others to avoid making mistakes, is called 'Analytical.'

The third 'How' factor consists of items that express participatory behaviors such as proposing subjective solutions to problems, bringing different perspectives, making different interpretations, presenting ideas in a systematic order, and making the discussion subjective by giving examples from one's own life. Individuals who demonstrate these participation behaviors are also interested in others' interpretations. However, this interest is not directed towards using them, but rather towards revealing what is different. It can be said that this group, which makes the discussion subjective by offering their own experiences, values both the other people in the environment and the content. However, they try to put forth what is new. This group and this factor are called 'Innovative.'

The fourth 'How' factor is composed of items expressing participation behaviors such as following only the comments that catch their interest, commenting in response to only recent comments, and commenting only by looking at the discussion question without reading the other comments. It is thought that individuals who exhibit these participation behaviors do not like to participate in online discussion environments. They perhaps participate in situations of necessity, or because of a sense of responsibility or social pressure. They also try to complete their tasks as quickly as possible. The individuals in this group and this factor are called 'Practical.'

When the factors and items that constitute the Why and How dimensions of participation style in online instructional discussions were examined, some parallels were observed regarding the structure of participation styles. For example, individuals who are in the environment to socialize may have connective features, such as wondering how they affect or 
Table 4 How dimension items

\begin{tabular}{|c|c|c|}
\hline No. & Item & Factor \\
\hline \multicolumn{3}{|c|}{ How dimension } \\
\hline i5 & I make comments that sum up other people's comments & Connective \\
\hline i6 & I send motivating messages to other people because of their comments & \\
\hline i7 & I spend a large part of my duration time to respond my friends' comments & \\
\hline i8 & $\begin{array}{l}\text { I prefer to be the first commentator in order not to repeat the opinion of } \\
\text { others }\end{array}$ & \\
\hline i9 & $\begin{array}{l}\text { I do conceptual excerpts from previous comments while making com- } \\
\text { ments }\end{array}$ & \\
\hline i13 & I engage in an intensive thinking process while making a comment & Analytical \\
\hline i14 & I spend a large part of my duration time for analyzing the comments & \\
\hline i15 & $\begin{array}{l}\text { I want to understand everything about the subject before making a com- } \\
\text { ment }\end{array}$ & \\
\hline i16 & I pay attention to writing styles while making a comment & \\
\hline $\mathrm{i} 21$ & I try to present my thoughts on the discussion topic in a systematic order & Innovative \\
\hline $\mathrm{i} 22$ & I propose solutions that represent my opinion while making a comment & \\
\hline $\mathrm{i} 23$ & I use personal experiences while making a comment & \\
\hline i24 & I redirect the discussion through bringing different perspectives & \\
\hline $\mathrm{i} 25$ & $\begin{array}{l}\text { I try to make as many as possible different interpretations of the discus- } \\
\text { sion topic }\end{array}$ & \\
\hline i29 & $\begin{array}{l}\text { I comment in response to the discussion question only, without following } \\
\text { any other comments }\end{array}$ & Practical \\
\hline $\mathrm{i} 30$ & I comment in response to the most recent comments only & \\
\hline i31 & I only follow comments that catch my interest & \\
\hline i32 & $\begin{array}{l}\text { I comment at the end of the thread because the last comments are more } \\
\text { important than others }\end{array}$ & \\
\hline
\end{tabular}

shape the environment, sending motivating messages, and quoting others. Similarly, since those who are in the environment to interact with the content are completely focused on the content, they tend to spend most of their time in the environment studying comments or going through intense thought processes; in other words, they tend to perform analyses. Hence, they tend to participate analytically, too. Individuals who are in the environment to discuss tend to participate when there is a difference or originality, or they participate by creating a difference in the environment. Those who are in the environment for fulfilling requirements will want to show that they exist in the quickest way possible since they participate only because of their responsibility towards the class or their friends. In other words, they will prove their existence in a practical way.

Thus, it is thought that there is a relationship between the participation reason and the participation form as mentioned above. The participation styles were accordingly defined as 'To Socialize/Connective,' 'To Get Information/Analytical,' 'To Discuss/Innovative,' and 'To Fulfill Requirements/Practical.' 


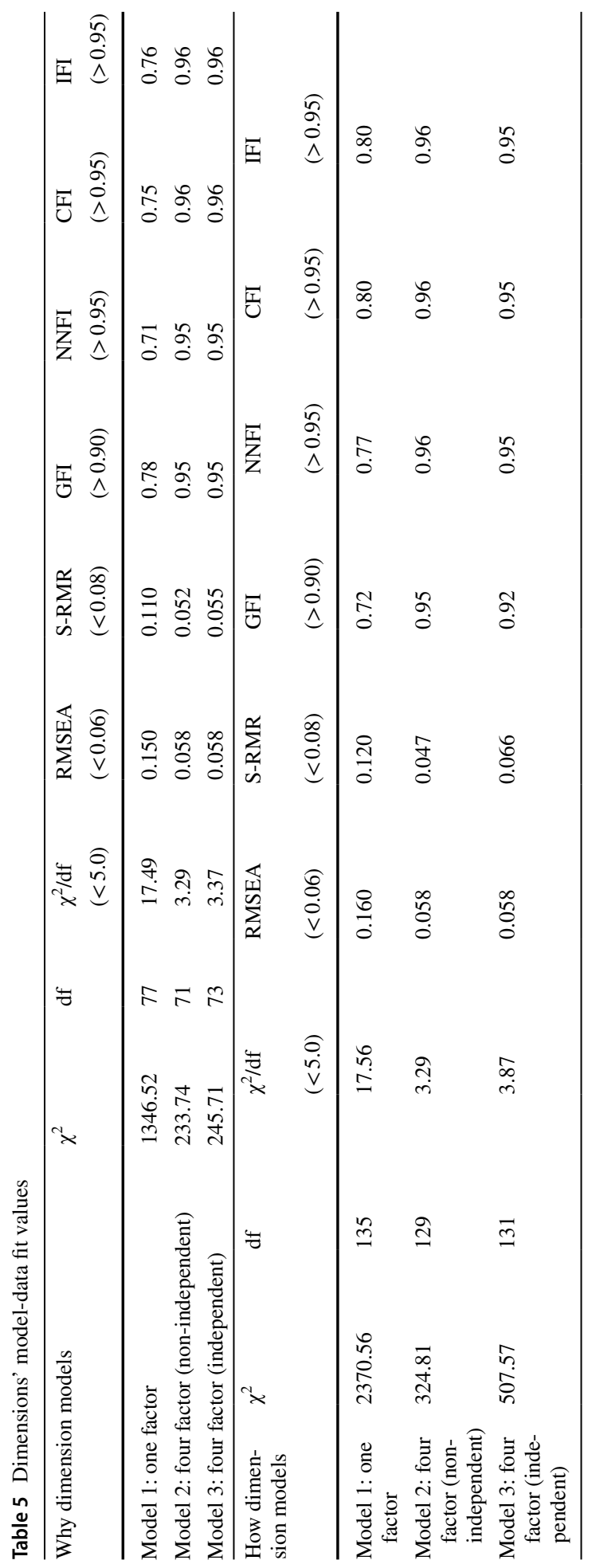


Table 6 The Scale's fit values

\begin{tabular}{llllllllll}
\hline $\begin{array}{l}\text { Participation style } \\
\text { model }\end{array}$ & $\chi^{2}$ & df & $\begin{array}{l}\chi^{2} / \mathrm{df} \\
(<5.0)\end{array}$ & $\begin{array}{l}\text { RMSEA } \\
(<0.06)\end{array}$ & $\begin{array}{l}\text { S-RMR } \\
(<0.08)\end{array}$ & $\begin{array}{l}\text { GFI } \\
(>0.90)\end{array}$ & $\begin{array}{l}\text { NNFI } \\
(>0.95)\end{array}$ & $\begin{array}{l}\text { CFI } \\
(>0.95)\end{array}$ & $\begin{array}{l}\text { IFI } \\
(>0.95)\end{array}$ \\
\hline $\begin{array}{l}\text { Modelling the scale } \\
\text { (second level) }\end{array}$ & 1254.84 & 446 & 2.81 & 0.051 & 0.063 & 0.90 & 0.96 & 0.97 & 0.97 \\
\hline
\end{tabular}

\section{Confirmatory factor analysis results}

According to Jackson et al. (2009), the comparative fit index (CFI, 78.4\%), root mean square error of approximation (RMSEA, 64.9\%), and Tucker-Lewis index (TLI, 46.4\%) are the most commonly used values after the chi-square value while reporting confirmatory factor analyses. DiStefano and Hess (2005) stated that non-normed fit index (NNFI), incremental fit index (IFI), goodness-of-fit index (GFI), and standardized root-mean-square residual (S-RMR) values were also commonly reported. In this study, the most commonly reported values in the literature, i.e., chi-square $\left(\chi^{2}\right)$, degrees of freedom (df), ratio of chisquare to degrees of freedom $\left(\chi^{2} / \mathrm{df}\right)$, RMSEA, GFI, S-RMR, NNFI, CFI, and IFI values are reported.

The fit values and the reference values (Schermelleh-Engel et al. 2003; West et al. 2012) obtained from the CFA regarding the Why and How dimensions are given in Table 5.

As can be seen in Table 5, in the first stage, a model wherein 14 Why items predicted a single factor was developed, and it was determined that the fit indices did not produce appropriate values. This result indicated that the dataset did not fit the single-factor model and the Why dimension consisted of multiple factors. In the next stage, defined according to the item-structure relationships obtained from the EFA, models wherein four factors were not non-independent (Model 2) and independent (Model 3) were tested. It was found that the results obtained from these procedures were better than those for Model 1, and the fit indices of the models were found to be sufficient. The same modeling method was repeated for the How dimension, and similar results were reached. Model 3 was selected for both dimensions.

As a result of these findings, the study was continued with four non-independent factors for both the Why and the How dimension, with a total of eight factors. To determine whether the Why (To Socialize, To Get Information, To Discuss, To Fulfill Requirements) and How (Connective, Analytical, Innovative, Practical) dimensions obtained by first-level confirmatory factor analyses would relate so as to represent the participation variable as an above concept, second-level CFA was conducted (Büyüköztürk 2010).

In the last stage, why and how participation is undertaken was theoretically modeled. The fit indices are presented in Table 6.

As can be seen in Table 6, according to the data obtained from the second-level CFA, the participation style scale has acceptable values. The item error variances, factor loadings, and correlation values between the factors and standardized coefficients and t values obtained as a result of CFA are given in Figs. 1 and 2, respectively.

As can be seen in Fig. 2, the factor loadings of the items were between 0.42 and 0.79 , and these factor loadings were statistically significant according to the $t$ values. The scale consists of 32 items, and only one item is below 0.50 . 


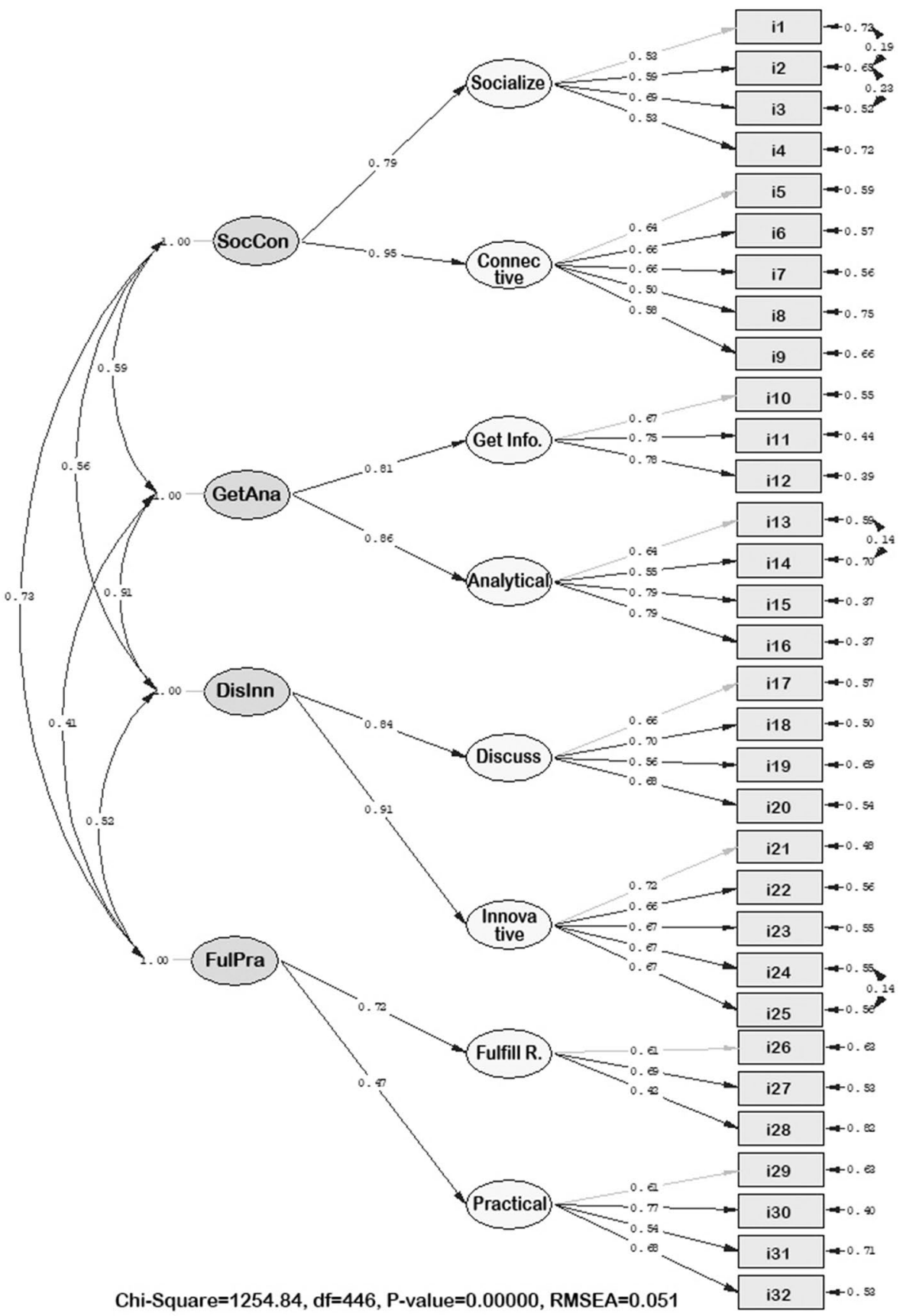

Fig. 1 Standardized coefficients as a result of CFA. SocCon to socialize/connective, GetAna to get information/analytical, DisInn to discuss/innovative, FulPra to fulfill requirements/practical 


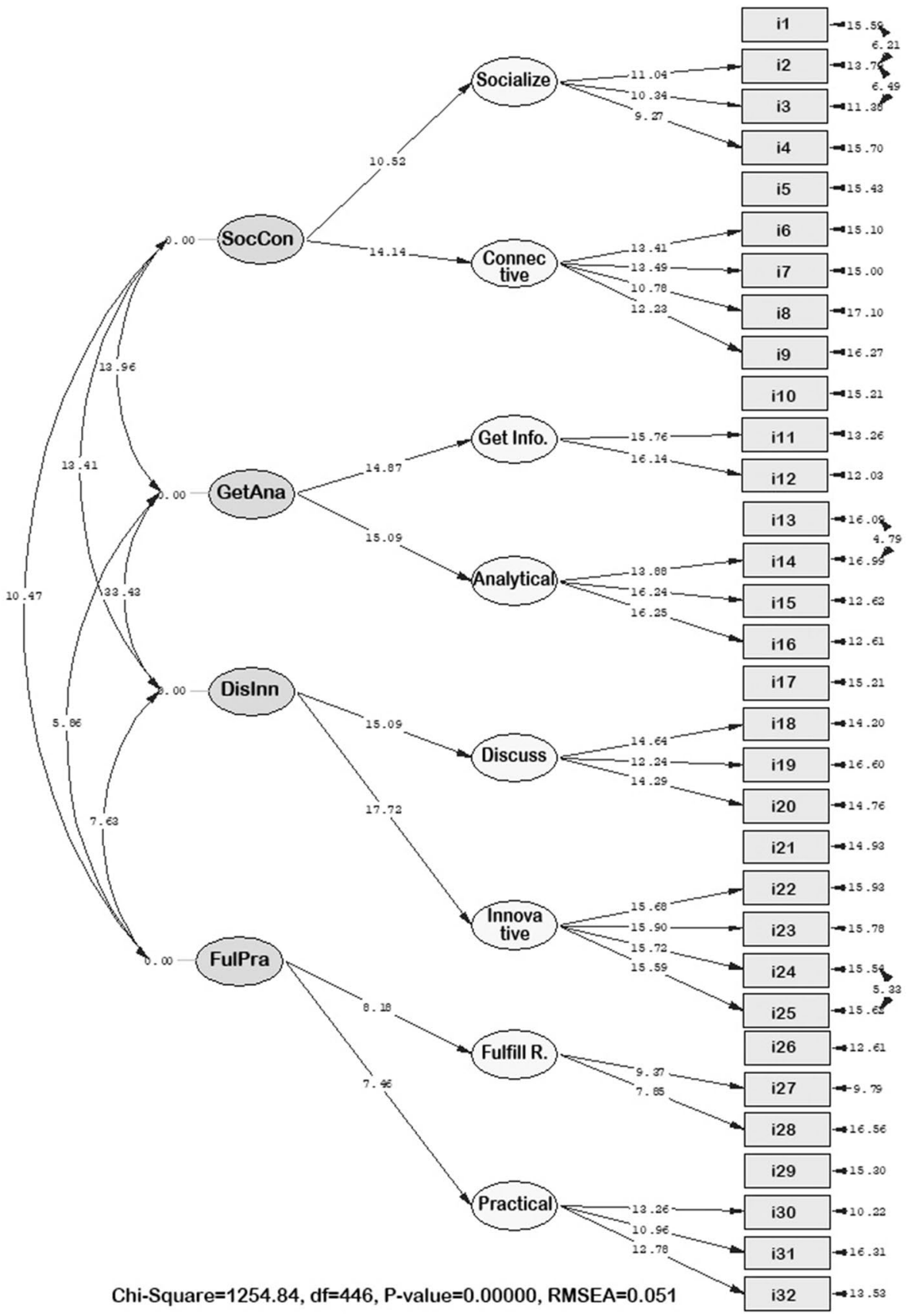

Fig. 2 T-values as a result of CFA. SocCon to socialize/connective, GetAna to get information/analytical, DisInn to discuss/innovative, FulPra to fulfill requirements/practical 
Table 7 The Scale's reliability coefficients

\begin{tabular}{lll}
\hline Factor & Cronbach's Alpha & Items \\
\hline To socialize/connective & 0.81 & 9 \\
To get information/analytical & 0.83 & 7 \\
To discuss/innovative & 0.85 & 9 \\
To fulfill requirements/practical & 0.70 & 7 \\
Participation styles scale for online & 0.89 & 32 \\
$\quad$ instructional discussion & & \\
\hline
\end{tabular}

\section{Validity and reliability results of the scale}

Factorial validity of the Participation Style Scale for Online Instructional Discussions was proved by EFA and CFA. However, the internal consistency reliability of the scale was examined with Cronbach's alpha coefficient. Cronbach's alpha coefficient was tested for reliability of the scale, and the reliability coefficients are presented in Table 7.

\section{Implementation of the scale}

The Why and How dimensions of the developed scale can be applied separately or can be used together. EFA shows that they can be used separately and CFA shows that they can be used together. Scale items were prepared in 5-point Likert type. The options were 0 ('not suitable for me at all'), 1 ('not suitable for me'), 2 ('undecided'), 3 ('suitable for me'), and 4 ('very suitable for me').

The scores that students get from the scale are calculated according to the factors of the dimensions and then it is determined which participation style the student has the most points for. We assume that the participation style for which he or she gets the most points is the student's predominant or weighted participation style. For example, when we examine the Why and How dimensions of the scale separately, the scale's score can be calculated by summing the item points. When the Why and How dimensions are used together, the predominant participation style is determined by taking the average of the item points.

\section{Discussion}

Online instructional discussions are critical practices since they are created by integrating participant-managed online environments into learning and instruction processes and since they ensure the continuity of learning independent of space and time. These applications, which can be called computer-, technology-, Internet-, or network-based discussions, can lead to effective learning if they are well organized. Research reveals that computermediated asynchronous discussions make significant contributions to the understanding of learning content if they are well organized (Garrison et al. 2001; Liu et al. 2020). Online discussions encourage students to participate, positively influence learning, enhance satisfaction and persistence, and support student-centered learning (Alavi and Dufner 2005; Citera 1998; Davies and Graff 2005). However, as highlighted above, the effectiveness of online instructional discussions is conditional on being well organized. At least one aspect of good organization is to understand all the participants, because, as in face-to-face environments, the principle of individual differences remains valid in these environments, too. 
Participants show different characteristics and can be categorized according to the characteristics they show in many aspects, from preference to participate or not in the environment to reasons for participation or motivating factors and to the types of participation. When the participant categories identified by studies based on the forms of participation in online discussions are examined, it is seen that the Why and How dimensions are used in the definitions, although they are not considered separately (Bento et al. 2005; Bento and Schuster 2003; Dowell et al. 2015; Phirangee et al. 2016; Rafaeli and Ariel 2008; Ruthotto et al. 2020; Taylor 2002; Yang and Richardson 2008; Zuckerman et al. 2009; Wise et al. 2014). From this point of view, this study was carried out in order to redefine these two dimensions separately, to reveal the related structures between them, and to define participation styles accordingly. In this study, it was aimed to determine the participation styles in online instructional discussions and accordingly develop a standardized measurement tool to categorize learners. The characteristics of the scale, which is called the Participation Style Scale for Online Instructional Discussions, are as follows.

The Participation Style Scale for Online Instructional Discussions is basically composed of two dimensions: Why and How. The Why dimension pertains to the reasons or motivations of learners to participate in online discussion environments, and the How dimension pertains to participation forms or behaviors. This is similar to the study of Kolb (1985), which developed an inventory of learning styles based on the preferences of individuals in the process of receiving and transforming information, based on an experiential learning model. The structure is based on the idea that these two dimensions together form the participation style as per the relevant literature. The EFA revealed that the scale consisted of eight factors, namely four Why and four How factors. The Why factors are called To Socialize, To Get Information, To Discuss, and To Fulfill Requirements, whereas the How factors are called Connective, Analytical, Innovative, and Practical. When the Why and How dimensions are taken together, the participation styles are called To Socialize/Connective, To Get Information/Analytical, To Discuss/Innovative, and To Fulfill Requirements/Practical.

\section{Participation styles determined by the scale}

\section{To socialize/connective}

For those individuals who participate in online environments to socialize and show connective behaviors, other people in the environment and social interactions are important. They are more active than others because they are motivated to receive attention, get feedback on their comments, and make others confirm their views. They take into account other comments and make excerpts from them. They send motivating messages like full participants, as Kim and Ketenci (2019) stated. They are more interested in the comments of others than content. In our opinion, by making inferences from the comments of the other participants in the discussion and inspiring others, they affect the discussion, move the discussion topic in the way they want, and bind the participants into the discussion. The characteristics of these participants resemble those of 'Coverage' participants as specified by Wise, Hausknecht, and Zhao (2014). In the literature (Bento et al. 2005; Bento and Schuster 2003; Zuckerman et al. 2009), social participants are frequently seen as a category. Taking advantage of such participatory roles, such as those in the supportive style that Sansone et al. (2018) identified in their work, can provide opportunities for effective learning and encourage the participation and motivation of group mates. As Lin et al. (2019) and John and Meinel (2020) stated, the fact that women are in a group may be another factor that 
may increase interactions. Making some efforts to increase the interactions of a group with the content should be a point that instructors pay attention to. In addition, having features such as instant notifications and likes can increase the interactions of learners with this participation style.

\section{To get information/analytical}

Individuals who participate in the environment to get information, read seriously (Poellhuber et al. 2019), and follow an analytical approach are interested in the discussion questions and the conceptual interpretations made in the context of these questions. Other people's comments are valuable only if they are relevant to the content. Before commenting, these individuals tend to try to understand the subject thoroughly and think in detail, and they find it important to be understandable. They go through a more analytical thinking process than others to avoid making mistakes and because of this they expect to write fewer messages, as Wise et al. (2014) stated for their participant group named 'Focused.' The presence of the instructor in the environment is important for this group. For example, Phirangee et al. (2016) stated that the students participated more in instructor-facilitated online courses where they wrote more notes, edited and reread notes more, and created more connections to other notes, and behavioral and cognitive engagements are also increased (Xu et al. 2020). This will have the advantages of generating more accurate content and being corrected by the instructors in the case of mistakes, and these participants also feel more supported (Epp et al. 2017). Therefore, different facilitation methods or the empowering of students to manage contextual discussions (Pala and Erdem 2011; Cheng et al. 2020) can be used to increase the interaction and participation of the learners. Student-instructor interaction is more important for these individuals than group interactions (Moore 1989). It may be meaningful that the implicit participants described by Bento and Schuster (2003) and Gerbic (2006) and those students who show the educational style characteristics of Sansone et al. (2018) are directed towards dealing with others. The need to increase interaction is often emphasized for effective learning in an online environment (Ho 2002).

\section{To discuss/innovative}

These individuals, who participate in online environments to ensure authentic learning and show innovative tendencies, are interested in both content and others' comments. However, their way of dealing with and their expectations from the environment may make them be viewed as conditional participants. In fact, the participants in this group tend to participate in the discussion only if they feel they need to make a statement, if they have a different view from the shared comments, if they think that the discussion will benefit them, if they see the group as a source of learning (Sansone et al. 2018), or if they find questions triggering discussion. It is thought that this group, which is concerned with the discussion questions and the desire of producing a different opinion from others' comments, sees or wants to see online environments as environments where different and authentic discussions are held and learned from. This group wants to bring difference and subjectivity to the environment with subjective solutions, different perspectives and interpretations, and personal experiences. It may be important to direct this group more towards content and towards the views of others for their own values. On the other hand, students with this style can be used to stop online discussions from being a series of repetitive comments. Interfaces supported by learning analytics that use 
artificial intelligence to analyze similar words can also be used as a precaution against repetitive discussion comments and structures (Marbouti and Wise 2016).

\section{To fulfill requirements/practical}

Participating in online discussion environments as a requirement of a task and showing practical tendencies, this group does not participate willingly in discussions or does not participate in line with aims determined by themselves, but rather participate in line with external factors. Participation is a perceptual or real task for them. Even if the participation is not compulsory, they participate in the discussion due to responsibility towards the course, towards other participants, or towards the instructor. Described as 'self-assessors' by Poellhuber et al. (2019) or 'Outsiders' by Phirangee et al. (2016), these participants enter the environment when necessary and complete an exam or a similar task or perform the minimum activity required by the course. Mason (2011) states that some participants feel guilty for not participating in the online discussion despite participation being on a voluntary basis. These participants can choose to follow the comments that interest them, choose to respond to the final comment, or just comment on the discussion question. These are sufficient to complete a task and to fulfill their responsibility for participation. If there are no solutions that make online environments attractive for this group, which is quite similar to the 'shirkers' described by Taylor (2002), it can be said that learning will not be productive for them. Therefore, it should be ensured that the instructions are clear and access to the system is possible with minimal effort for these participants.

\section{Conclusion}

As described above, the Participation Style Scale for Online Instructional Discussions developed in this study was able to determine four participation styles. Of course, there may be other styles. However, these four styles can contribute to educators who want to understand the different behaviors of the students in the instructional discussion environment, albeit partially, and guide them for more effective learning.

At the same time, learners who think and gain awareness about their own participation styles can manage their discussion and learning processes more effectively. This is thought to be important for educational systems that try to create learner-oriented learning environments.

\section{Limitations and suggestions}

The present study groups consisted of undergraduate and graduate students who were studying at different Turkish universities, mainly in the Computer Education and Instructional Technologies Department. Thus, it is recommended to repeat the study with more diverse student groups. Adapting the scale to different cultures and languages may also produce different results; the Why and How dimensions can give different results in different cultures. Different sub-dimensions of the scale could be utilized differently from our predictions and different results could be obtained.

In addition, as we know that the size of the class affects participation in discussions (Chen and Liu 2020; Cheng et al. 2020), it is recommended to repeat the study with different class sizes. 


\section{References}

Alavi, M., \& Dufner, D. (2005). Technology-mediated collaborative learning: A research perspective. In S. R. Hiltz \& R. Goldman (Eds.), Learning together online: Research on asynchronous learning networks (pp. 191-213). New Jersey: Lawrence Erlbaum Associates Inc.

Bento, R., Brownstein, B., Kemery, E., \& Zacur, S. R. (2005). A taxonomy of participation in online courses. Journal of College Teaching \& Learning, 2(12), 79-86.

Bento, R., \& Schuster, C. (2003). Participation: The online challenge. In A. K. Aggarwal (Ed.), Web-based education: Learning from experience (pp. 156-164). Hershey, PA: IGI-Global.

Berge, Z. L. (1995). The role of the online instructor/facilitator. Educational Technology, 35(1), 22-30.

Butcher, T., Read, M. F., Jensen, A. E., Morel, G. M., Nagurney, A., \& Smith, P. A. (2020). Using an AISupported Online Discussion Forum to Deepen Learning. Handbook of research on online discussionbased teaching methods (pp. 380-408). IGI Global: Hershey, PA.

Büyüköztürk, Ş. (2010). Sosyal bilimler için veri analizi el kitabı: İstatistik, araştırma deseni, SPSS uygulamalarl ve yorum. Ankara: Pegem Akademi Yayınları.

Chen, L. T., \& Liu, L. (2020). Social presence in multidimensional online discussion: The roles of group size and requirements for discussions. Computers in the Schools, 37(2), 116-140.

Cheng, S. C., Hwang, G. J., \& Lai, C. L. (2020). Effects of the group leadership promotion approach on students' higher order thinking awareness and online interactive behavioral patterns in a blended learning environment. Interactive Learning Environments, 28(2), 246-263.

Cheong, C. M., \& Cheung, W. S. (2008). Online discussion and critical thinking skills: A case study in a Singapore secondary school. Australasian Journal of Educational Technology, 24(5), 556-573.

Citera, M. (1998). Distributed teamwork: The impact of communication media on influence and decision quality. Journal of the American Society for Information Science, 49(9), 792-800.

Çokluk, Ö., Şekercioğlu, G., \& Büyüköztürk, Ş. (2010). Sosyal bilimler için çok değişkenli istatistik: SPSS ve LISREL uygulamaları. Ankara: Pegem Akademi Yayınları.

Daniel, S. J. (2020). Education and the COVID-19 pandemic. Prospects. https://doi.org/10.1007/s1112 5-020-09464-3.

Davies, J., \& Graff, M. (2005). Performance in e-learning: Online participation and student grades. British Journal of Educational Technology, 36(4), 657-663.

DiStefano, C., \& Hess, B. (2005). Using confirmatory factor analysis for construct validation: An empirical review. Journal of Psychoeducational Assessment, 23(3), 225-241.

Dowell, N. M., Skrypnyk, O., Joksimovic, S., Graesser, A. C., Dawson, S., Gaševic, D., Hennis, A., T., De vries, P., \& Kovanovic, V. (2015, June). Modeling Learners' Social Centrality and Performance through Language and Discourse. In Proceedings of the 8th International Conference on Educational Data Mining, (pp. 250-257).

Epp, C. D., Phirangee, K., \& Hewitt, J. (2017). Talk with me: Student pronoun use as an indicator of discourse health. Journal of Learning Analytics, 4(3), 47-75.

Garrison, D. R., Anderson, T., \& Archer, W. (1999). Critical inquiry in a text-based environment: Computer conferencing in higher education. The internet and higher education, 2(2-3), 87-105.

Garrison, D. R., Anderson, T., \& Archer, W. (2001). Critical thinking, cognitive presence, and computer conferencing in distance education. American Journal of Distance Education, 15(1), 7-23.

Gerbic, P. (2006). To post or not to post: Undergraduate student perceptions about participating in online discussions. In Markauskaite, L., Goodyear, P. and Reimann (Eds.), Who's learning? Whose technology? Proceedings of the 23rd Annual Conference of the Australasian Society for Computers in Learning in Tertiary Education (pp. 271-281). Sydney: Sydney University Press.

Hew, K. F., \& Cheung, W. S. (2012). Student participation in online discussions: Challenges, solutions, and future research. New York: Springer.

Ho, S. (2002, July). Evaluating students' participation in on-line discussions. Paper presented at the The Eighth Australian World Wide Web Conference (AusWeb 2002), Sunshine Coast, Queensland.

Hodges, C., Moore, S., Lockee, B., Trust, T., \& Bond, A. (2020). The difference between emergency remote teaching and online learning. Educause Review, 27.

Hrastinski, S. (2006). Introducing an informal synchronous medium in a distance learning course: How is participation affected? The Internet and Higher Education, 9(2), 117-131. https://doi. org/10.1016/j.iheduc.2006.03.006.

Hrastinski, S. (2008a). The potential of synchronous communication to enhance participation in online discussions: A case study of two e-learning courses. Information \& Management, 45(7), 499-506. https://doi.org/10.1016/j.im.2008.07.005.

Hrastinski, S. (2008b). What is online learner participation? A literature review. Computers \& Education, 51(4), 1755-1765. https://doi.org/10.1016/j.compedu.2008.05.005. 
Hrastinski, S. (2009). A theory of online learning as online participation. Computers \& Education, 52(1), 78-82. https://doi.org/10.1016/j.compedu.2008.06.009.

Huang, R. H., Liu, D. J., Tlili, A., Yang, J. F., Wang, H. H., et al. (2020). Handbook on facilitating flexible learning during educational disruption: The Chinese experience in maintaining undisrupted learning in covid-19 outbreak. Beijing: Smart Learning Institute of Beijing Normal University.

Huck, S. W. (2012). Reading statistics and research (6th ed.). Boston, MA: Pearson.

Jackson, D. L., Gillaspy, J. A., Jr., \& Purc-Stephenson, R. (2009). Reporting practices in confirmatory factor analysis: An overview and some recommendations. Psychological Methods, 14(1), 6-23.

John, C., \& Meinel, C. (2020, April). Learning Behavior of Men and Women in MOOC Discussion Forums-A Case Study. In 2020 IEEE Global Engineering Education Conference (EDUCON) (pp. 300-307). IEEE.

Joksimović, S., Dowell, N., Skrypnyk, O., Kovanović, V., Gašević, D., Dawson, S., \& Graesser, A. C. (2015, March). How do you connect? Analysis of Social Capital Accumulation in connectivist MOOCs. In Proceedings of the Fifth International Conference on Learning Analytics and Knowledge (pp. 64-68).

Kim, M. K., \& Ketenci, T. (2019). Learner participation profiles in an asynchronous online collaboration context. The Internet and Higher Education, 41, 62-76.

Kolb, D. A. (1985). LSI (Learning Style Inventory): Users guide. Boston, MA: McBer \& Company.

Lin, Y., Dowell, N., Godfrey, A., Choi, H., \& Brooks, C. (2019, March). Modeling gender dynamics in intra and interpersonal interactions during online collaborative learning. In Proceedings of the 9th International Conference on Learning Analytics \& Knowledge (pp. 431-435).

Liu, Z., Liu, S., Zhang, C., Su, Z., Hu, T., \& Liu, S. (2020). Investigating the Relationship between Learners' Cognitive Participation and Learning Outcome in Asynchronous Online Discussion Forums. In CSEDU (2) (pp. 26-33).

Marbouti, F., \& Wise, A. F. (2016). Starburst: A new graphical interface to support purposeful attention to others' posts in online discussions. Educational Technology Research and Development, 64(1), 87-113.

Mason, R. B. (2011). Student engagement with, and participation in, an e-Forum. Educational Technology \& Society, 14(2), 258-268.

Moore, M. G. (1989). Editorial: Three types of interaction. American Journal of Distance Education, 3(2), 1-7. https://doi.org/10.1080/08923648909526659.

Osborne, J. W. (2015). What is rotating in exploratory factor analysis. Practical Assessment, Research \& Evaluation, 20(2), 1-7.

Pala, F. K., \& Erdem, M. (2011). Investigation of participation in student-led online discussion with respect to management responsibility and learning styles. Hacettepe University Journal of Education, 41, 360-371.

Pala, F. K., \& Erdem, M. (2015a). Opinions of pre-service teachers on online discussion environments. Turkish Online Journal of Qualitative Inquiry, 6(2), 24-47.

Pala, F. K., \& Erdem, M. (2015b). Çevrimiçi öğrenme ortamları ve katılım. In B. Akkoyunlu, A. İşman, \& H. F. Odabaşı (Eds.), Ĕgitim Teknolojileri Okumaları 2015 (pp. 213-232). Ankara: TOJET.

Phirangee, K., Epp, C. D., \& Hewitt, J. (2016). Exploring the relationships between facilitation methods, students' sense of community, and their online behaviors. Online Learning, 20(2), 134-154.

Poellhuber, B., Roy, N., \& Bouchoucha, I. (2019). Understanding participant's behavior in massively open online courses. International Review of Research in Open and Distributed Learning. https:// doi.org/10.7202/1057981ar.

Rafaeli, S., \& Ariel, Y. (2008). Online motivational factors: Incentives for participation and contribution in wikipedia. In A. Barak (Ed.), Psychological aspects of cyberspace: Theory, research, applications (pp. 243-267). Cambridge: Cambridge University Press.

Reich, J. et. al. (2020). Remote Learning Guidance from State Education Agencies during the COVID-19 Pandemic: A First Look. Retrieved from osf.io/k6zxy/

Rosé, C. P., \& Ferschke, O. (2016). Technology support for discussion based learning: From computer supported collaborative learning to the future of massive open online courses. International Journal of Artificial Intelligence in Education, 26(2), 660-678.

Ruthotto, I., Kreth, Q., Stevens, J., Trively, C., \& Melkers, J. (2020). Lurking and participation in the virtual classroom: The effects of gender, race, and age among graduate students in computer science. Computers \& Education, 151, 103854.

Sansone, N., Ligorio, M. B., \& Buglass, S. L. (2018). Peer e-tutoring: Effects on students' participation and interaction style in online courses. Innovations in Education and Teaching International, 55(1), $13-22$. 
Schermelleh-Engel, K., Moosbrugger, H., \& Müller, H. (2003). Evaluating the fit of structural equation models: Tests of significance and descriptive goodness-of-fit measures. Methods of Psychological Research Online, 8(2), 23-74.

Song, D., Rice, M., \& Oh, E. (2019). Participation in online courses and interaction with a virtual agent. International Review of Research in Open and Distributed Learning. https://doi.org/10.7202/10579 $71 \mathrm{ar}$.

Tabachnick, B. G., \& ve Fidell, L. S. (2012). Using multivariate statistics (6th ed.). New Jersey: Pearson.

Taylor, J. C. (2002, June). Teaching and learning online: The workers, the lurkers and the shirkers. Paper presented at the Research in Distance \& Adult Learning in Asia: CRIDALA, Hong Kong.

Toquero, C. M. (2020). Challenges and opportunities for higher education amid the COVID-19 pandemic: The Philippine context. Pedagogical Research, 5(4), 63.

UNESCO. (2020). School closures caused by Coronavirus (Covid-19). Retrieved from https://en.unesc o.org/covid19/educationresponse

West, S. G., Taylor, A. B., \& Wu, W. (2012). Model fit and model selection in structural equation modeling. In R. H. Hoyle (Ed.), Handbook of structural equation modeling (pp. 209-231). New York: Guilford Press.

Wise, A. F., \& Cui, Y. (2018). Learning communities in the crowd: Characteristics of content related interactions and social relationships in MOOC discussion forums. Computers \& Education, 122, $221-242$.

Wise, A. F., Hausknecht, S. N., \& Zhao, Y. (2014). Attending to others' posts in asynchronous discussions: Learners' online "listening" and its relationship to speaking. International Journal of Computer-Supported Collaborative Learning, 9(2), 185-209.

$\mathrm{Xu}, \mathrm{B}$., Chen, N. S., \& Chen, G. (2020). Effects of teacher role on student engagement in WeChat-Based online discussion learning. Computers \& Education. https://doi.org/10.1016/j.compedu.2020.10395 6.

Yang, D., \& Richardson, J. C. (2008). Students' online interaction styles: Can they change? Journal of Educational Technology Development and Exchange, 1(1), 1-12.

Zuckerman, O., Blau, I., \& Monroy-Hernández, A. (2009). Children's participation patterns in online communities: An analysis of Israeli learners in the scratch online community. Interdisciplinary Journal of E-Learning and Learning Objects, 5, 263-274.

Publisher's Note Springer Nature remains neutral with regard to jurisdictional claims in published maps and institutional affiliations.

Ferhat Kadir Pala received his undergraduate degree in 2000 from Middle East Technical University, Faculty of Education, Department of Computer Education, his master's degree in 2006 from Gazi University, Faculty of Technical Education, Department of Electronics and Computer Education, and his PhD degree in 2014 from Hacettepe University, Faculty of Education, Computer Education and Instructional Technologies Department. Between 2012-2013, he worked as a visiting scholar in the Department of Educational Psychology and Learning Systems at Florida State University and took part in some projects. Since 2014, he has been working as an Assistant Professor at Aksaray University, Department of Computer Education and Instructional Technologies. His main areas of interest are online learning, online learning environments, online participation, interaction, robotics, usability and the use of haptic technologies in education.

Mukaddes Erdem is a faculty member at Hacettepe University, Faculty of Education, Department of Computer Education and Instructional Technology. She has been working at Hacettepe University since 1988. She received her BS, MS and $\mathrm{PhD}$ degree from Educational Sciences. She continues his academic and scientific studies in Computer Education and Instructional Technology department. She lectures at undergraduate and graduate levels and manages theses. Within the scope of her scientific studies, she conducts researches, attends scientific meetings, and organizes seminars and workshops. Her main areas of interest are Learning Theories and Instructional Design, Learning Theories and New Technologies, Developing Learning Materials, Special Teaching Methods, Qualifications and Development of Online Learning Environments, Learner Behaviours and Reasons in Online Environment, Dynamics of Participation in Online Learning Environments, Learning Management, Online Learning Environments. 